\title{
AEROMAGNETIC MAP OF PART OF THE SALEM DEPOT QUADRANGLE, ROCKINGHAM COUNTY, NEW HAMPSHIRE AND ESSEX COUNTY, MASSACHUSETTS
}

\author{
GEOPHYSICAL INVESTIGATIONS \\ MAP GP- 712
}

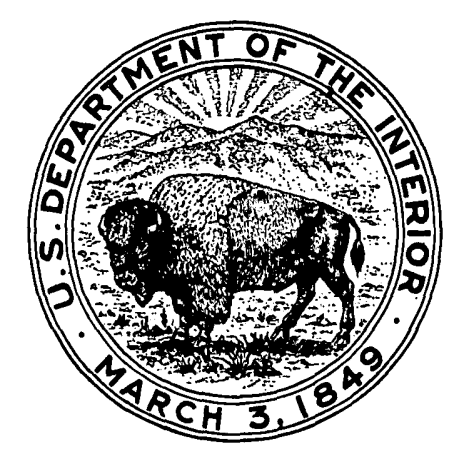

PUBLISHED BY THE U. S. GEOLOGICAL SURVEY 